\title{
ANÁLISE DE RESÍDUOS DE AGROTÓXICOS EM TOMATES EMPREGANDO DISPERSÃO DA MATRIZ EM FASE SÓLIDA (DMFS) E CROMATOGRAFIA GASOSA
}

\author{
Gevany P. Pinho \\ Campus Rio Paranaíba, Universidade Federal de Viçosa, 38810-000 Rio Paranaíba - MG, Brasil \\ Antônio A. Neves* e Maria Eliana L. R. Queiroz \\ Departamento de Química, Universidade Federal de Viçosa, 36570-000 Viçosa - MG, Brasil
}

Recebido em 23/1/08; aceito em 7/8/08; publicado na web em 18/12/08

\begin{abstract}
ANALYSIS OF PESTICIDE RESIDUE IN TOMATO USING MATRIX SOLID-PHASE DISPERSION (MSPD) AND GAS CHROMATOGRAPHY. This work was aimed on optimization of the matrix solid-phase dispersion (MSPD) technique using gas chromatography for analyzing residues of chlorpyriphos, $\lambda$-cyhalothrin, cypermethrin and deltamethrin in tomatoes. The results showed that silica was more efficient for the clean up of extracts, but florisil provided the highest recovery rates. A $2^{3}$ complete factorial design was carried out to evaluate the absorbent/sample ratio, presence of co-column (silica) and ultrasonic bath on the extraction rate. The percentage of extraction of the pesticides chlorpyriphos, $\lambda$-cyhalothrin, cypermethrin and deltamethrin were 64.7 , $88.3,99.2$ and $89.2 \%$, respectively, with relative standard deviations below $5 \%$.
\end{abstract}

Keywords: MSPD; pesticide; tomato.

\section{INTRODUÇÃO}

O tomate é uma das hortaliças de maior comercialização no país e muito apreciada pelo seu elevado valor nutritivo e facilidade no preparo. ${ }^{1}$ Entretanto, a cultura do tomate é muito susceptível ao ataque de pragas, em razão da grande área foliar e do microclima favorável criado pela planta que propiciam o desenvolvimento de insetos e doenças. ${ }^{2}$ Desse modo, para evitar perdas no rendimento das colheitas, vários tipos de agrotóxicos são utilizados no controle de pragas que atacam o tomateiro. Dentre os principais agrotóxicos utilizados neste tipo de cultura destacamse os piretróides deltametrina, cipermetrina e $\lambda$-cialotrina e o organofosforado clorpirifós, devido à alta eficiência destes como inseticidas. ${ }^{3}$ As estruturas desses compostos são apresentadas na Figura 1.

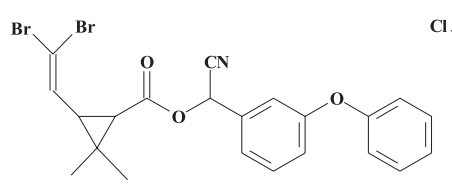

Deltametrina

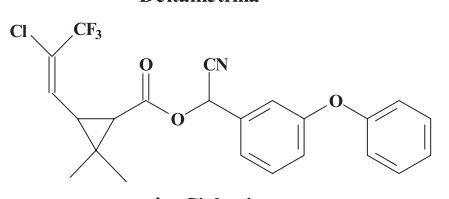

$\lambda$ - Cialotrina

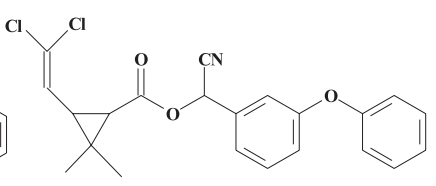

Cipermetrina

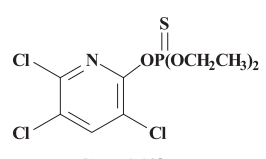

Clorpirifós
Figura 1. Estrutura da deltametrina, cipermetrina, $\lambda$-cialotina e clorpirifós

Quando aplicados de forma inadequada, resíduos desses compostos podem persistir no fruto, gerando uma importante rota de exposição humana. Em razão disso, a contaminação deste alimento tem sido alvo de constante preocupação no âmbito da saúde pública porque o tomate é um dos principais componentes da dieta dos brasileiros, sendo consumido in natura ou em processados. ${ }^{4}$

Os agrotóxicos quando ingeridos são potencialmente tóxicos ao

*e-mail: aneves@ufv.br homem. Por exemplo, resíduos de organofosforados podem causar efeitos adversos ao sistema nervoso central e periférico, ter ação imunodepressora, ser cancerígeno, etc. ${ }^{5,} 6$ Dessa forma, a análise quantitativa de resíduos destes inseticidas em tomates é necessária para conhecer os níveis de contaminação e avaliar se estão dentro dos limites máximos de resíduos (LMR) estabelecidos pela Agência Nacional de Vigilância Sanitária (ANVISA).

O método convencional usado para determinar resíduos de agrotóxicos em frutas e vegetais é baseado na extração com solvente, seguido por etapas de clean up. ${ }^{7}$ Entretanto, novas técnicas de extração têm sido aplicadas com a mesma finalidade como extração em fluido supercrítico (EFS), ${ }^{8}$ microextração em fase sólida (MEFS) ${ }^{9-11}$ e extração em fase sólida (EFS). ${ }^{12,13}$

Outra metodologia muito empregada em análise de matrizes complexas é a dispersão da matriz em fase sólida (DMFS), pois agrupa em uma única etapa a extração e o clean up dos extratos. O princípio da técnica foi introduzido em $1989^{14}$ para análise de contaminantes em tecidos animais, sendo empregada para análise de agrotóxicos em frutas e vegetais a partir de $1996 .{ }^{15}$ Esta técnica se baseia na dispersão da amostra sólida ou semi-sólida em um adsorvente, geralmente florisil ${ }^{16,17}$ ou octadecil (C-18). ${ }^{18,19}$ Além destes adsorventes, têm sido utilizados também terra de diatomáceas, ${ }^{20}$ sílica $^{21}$ e octil $(\mathrm{C}-8)^{22}$ na extração de agrotóxicos em alimentos.

Em geral, no desenvolvimento da DMFS, as condições ótimas de análise são obtidas por métodos clássicos univariados. No entanto, estes métodos não permitem avaliar as interações entre as variáveis a serem otimizadas. Alternativamente, pode-se recorrer aos métodos quimiométricos de análise multivariada, sendo o planejamento fatorial uma das formas mais eficientes para investigar as influências de todas as variáveis experimentais de interesse e os efeitos de interação nas respostas, utilizando poucos experimentos..$^{23,24}$

Neste trabalho foi otimizado um método para extrair os agrotóxi$\cos \lambda$-cialotrina, cipermetrina, deltametrina e clorpirifós de amostras de tomate empregando a DMFS, com condições experimentais determinadas empregando-se um planejamento fatorial $2^{3}$. A quantificação dos agrotóxicos foi feita por cromatografia gasosa com detecção por captura de elétrons (CG-ECD). 


\section{PARTE EXPERIMENTAL}

\section{Reagentes e soventes}

Os padrões dos agrotóxicos clorpirifós $(99,0 \% \mathrm{~m} / \mathrm{m}$ - Chem Service), cipermetrina $(92,4 \% \mathrm{~m} / \mathrm{m}$ - Chem Service), $\lambda$-cialotrina (86,5\% m/m - Syngenta) e deltametrina $(99,0 \% \mathrm{~m} / \mathrm{m}$ - Chem Service) e o padrão interno bifentrina $(92,2 \% \mathrm{~m} / \mathrm{m}$ - FMC do Brasil) foram utilizados neste estudo.

Os solventes acetonitrila (Mallinckrodt, grau HPLC) e acetato de etila (Mallinckrodt) foram empregados como extratores. Sulfato de sódio anidro (Mallinckrodt) foi empregado para eliminar água dos extratos. Os adsorventes florisil (J. B. Baker), sílica gel (Merck), 60-100 mesh foram condicionados com acetato de etila em banho ultra-sônico por $10 \mathrm{~min}$ e secos em estufa a $100^{\circ} \mathrm{C}$. Além desses adsorventes também foram utilizados octadecil (PR Cola) e octil (PR Cola).

\section{Soluções de agrotóxicos}

As soluções padrão estoque na concentração de $500,0 \mathrm{mg} \mathrm{L}^{-1}$ de clorpirifós, cipermetrina, -cialotrina e deltametrina foram preparadas individualmente em acetonitrila e armazenadas em freezer. A partir de diluição das soluções estoque foi preparada uma solução padrão de trabalho contendo os quatros agrotóxicos na concentração de 2,0 mg L L ${ }^{-1}$. Uma solução contendo apenas bifentrina (padrão interno) de concentração $2,0 \mathrm{mg} \mathrm{L}^{-1}$ foi preparada de forma semelhante aos demais padrões.

\section{Cartuchos}

Colunas de polietileno ( $7 \mathrm{~cm} \times 1,5 \mathrm{~cm}$ de d. i.) foram adaptadas a um sistema de multicomponentes de 12 entradas para cartuchos ( $\mathrm{Su}$ pelco), conectado a uma bomba de vácuo. Nos cartuchos foi colocada lã de vidro para reter a amostra dispersa no adsorvente.

\section{Equipamentos}

Foi utilizado um cromatógrafo a gás da Shimadzu (GC-17-A) equipado com um detector por captura de elétrons (DCE). A coluna capilar empregada na separação dos compostos foi uma HP-5 da Agilent Technologies, com fase estacionária composta de $5 \%$ de difenil e $95 \%$ de dimetilsiloxano, $30 \mathrm{~m}$ de comprimento; $0,25 \mathrm{~mm}$ de d. i. e $0,1 \mu \mathrm{m}$ de espessura de filme, sendo o nitrogênio o gás de arraste com vazão de $1,2 \mathrm{~mL} \mathrm{~min}^{-1}$. A programação de aquecimento da coluna iniciou em $150{ }^{\circ} \mathrm{C}$, com aumento de $10^{\circ} \mathrm{C} / \mathrm{min}$ até $290^{\circ} \mathrm{C}$, permanecendo nesta temperatura por $1 \mathrm{~min}$. $\mathrm{O}$ tempo total de análise foi de $15 \mathrm{~min}$. As temperaturas do injetor e detector foram mantidas, respectivamente, em 280 e $300{ }^{\circ} \mathrm{C}$. Um volume de $1 \mu \mathrm{L}$ de amostra foi injetado no cromatógrafo com razão de split 1:5.

Um banho ultra-sônico foi utilizado no procedimento de extração. O gerador deste aparato tem uma saída de $150 \mathrm{~W}$ e uma freqüência de $33 \mathrm{kHz}$.

\section{Preparo de amostras}

Amostras de tomates hidropônicas trituradas (isentas de agrotóxicos) foram fortificadas com $50 \mu \mathrm{L}$ da solução padrão de trabalho contendo os quatro agrotóxicos na concentração de $2,0 \mathrm{mg} \mathrm{L}^{-1}$ obtendo-se uma amostra fortificada com concentração de $0,20 \mu \mathrm{g}$ $\mathrm{g}^{-1}$, para o estudo da porcentagem de recuperação dos agrotóxicos. As amostras fortificadas foram deixadas em repouso por $3 \mathrm{~h}$, para evaporação do solvente e promover uma maior interação dos agrotóxicos com a amostra, antes da extração.

\section{Avaliação do adsorvente e eluente para a técnica de extração DMFS}

Amostras de tomates fortificadas, $0,5000 \mathrm{~g}$, foram colocadas em cápsula de porcelana acrescentou-se $0,5000 \mathrm{~g}$ de adsorvente e, em seguida, macerou-se a mistura até a completa dispersão da amostra. A mistura (amostra + adsorvente) na proporção de 1:1 foi transferida para uma coluna de polietileno (cartucho) de $10,0 \mathrm{~mL}$ contendo $1,0000 \mathrm{~g}$ de sulfato de sódio anidro. Adicionaram-se 10,0 $\mathrm{mL}$ do solvente de eluição ao cartucho em dois volumes iguais (5,0 $\mathrm{mL}+5,0 \mathrm{~mL}$ ). A vazão do solvente foi ajustado a uma vazão de aproximadamente $0,4 \mathrm{~mL} \mathrm{~min}^{-1}$. Ao extrato coletado acrescentou-se $50,0 \mu \mathrm{L}$ de solução de padrão interno (bifentrina) a $2,0 \mathrm{mg} \mathrm{L}^{-1}$. O solvente foi evaporado sob corrente de ar e o extrato recuperado em $1,0 \mathrm{~mL}$ de acetonitrila para análise cromatográfica. Este procedimento foi utilizado para avaliar a influência dos adsorventes e dos eluentes na porcentagem de recuperação dos agrotóxicos e na remoção de componentes da matriz.

Na Tabela 1 estão relacionados os 16 ensaios com as características dos adsorventes e eluentes usados na otimização da dispersão da matriz em fase sólida para extração dos agrotóxicos em tomate.

Tabela 1. Adsorventes e eluentes avaliados para otimização da DMFS

\begin{tabular}{lcc}
\hline Ensaios & Adsorventes & Eluentes \\
\hline 1 e 2 & Sílica & Acetato de etila \\
3 e 4 & Sílica & Hexano:Acetona $(9: 1)$ \\
5 e 6 & Florisil & Acetato de etila \\
7 e 8 & Florisil & Hexano:Acetona (9:1) \\
9 e 10 & C-18 & Acetato de etila \\
11 e 12 & C-18 & Hexano:Acetona (9:1) \\
13 e 14 & C-8 & Acetato de etila \\
15 e 16 & C-8 & Hexano:Acetona (9:1) \\
\hline
\end{tabular}

Avaliação do volume de solvente na extração dos agrotóxicos

Após definir o melhor adsorvente e eluente, verificou-se a influência do volume do solvente na remoção dos agrotóxicos da matriz. Para isso, foram eluídos volumes de $20,0 \mathrm{~mL}$ de solvente divididos em duas etapas de 10,0 mL. Os extratos obtidos foram analisados por cromatografia gasosa com um detector por captura de elétrons.

\section{Planejamento fatorial}

A técnica de DMFS foi submetida a uma nova etapa de otimização para a extração dos quatro agrotóxicos: clorpirifós, -cialotrina, cipermetrina e deltametrina, em amostra de tomate fortificada com padrões dos agrotóxicos. Na otimização foi adotado um planejamento fatorial completo, $2^{3}$, para avaliação do comportamento simultâneo de três fatores: proporção entre a quantidade de adsorvente e amostra, utilização de co-coluna e banho ultra-sônico. Os três fatores foram estudados em dois níveis (Tabela 2) e as análises foram realizadas em duplicata.

Estes fatores foram escolhidos porque a proporção entre as quantidades de adsorvente e amostra pode influenciar na eficiência da extração dos agrotóxicos e apresenta uma tendência de melhora nos rendimentos quando a proporção é aumentada. ${ }^{25} \mathrm{~A}$ presença de co-coluna e a exposição dos cartuchos ao banho ultra-sônico são fatores qualitativos, que podem influenciar, positiva ou negativamente, 
Tabela 2. Planejamento fatorial $2^{3}$ para amostras de tomate fortificadas $\left(0,20 \mu \mathrm{g} \mathrm{g}^{-1}\right)$

\begin{tabular}{lcccccc}
\hline \multicolumn{3}{c}{ Fatores codificados } & \multicolumn{3}{c}{ Fatores originais } \\
Ensaios & F(1) & $F(2)$ & $F(3)$ & $\begin{array}{c}\text { Adsorvente/ } \\
\text { Amostra (1) }\end{array}$ & $\begin{array}{c}\text { Co-coluna } \\
(2)\end{array}$ & $\begin{array}{c}\text { Banho ultra- } \\
\text { sônico (3) }\end{array}$ \\
\hline 1 e 2 & - & - & - & $1: 1$ & sem & sem \\
3 e 4 & + & - & - & $2: 1$ & sem & sem \\
5 e 6 & - & + & - & $1: 1$ & com & sem \\
7 e 8 & + & + & - & $2: 1$ & com & sem \\
9 e 10 & - & - & + & $1: 1$ & sem & com \\
11 e 12 & + & - & + & $2: 1$ & sem & com \\
13 e 14 & - & + & + & $1: 1$ & com & com \\
15 e 16 & + & + & + & $2: 1$ & com & com \\
\hline
\end{tabular}

na porcentagem de recuperação de cada agrotóxico.

Em cápsula de porcelana foi adicionado 0,5000 g de amostra de tomate hidropônico fortificada com os agrotóxicos. Acrescentou-se $0,5000 \mathrm{ou} 1,0000 \mathrm{~g}$ do adsorvente florisil para os ensaios correspondentes aos níveis (-) e (+), respectivamente (Tabela 2). Triturou-se a mistura até completa dispersão da matriz, sendo transferida, em seguida, para um cartucho contendo sulfato de sódio anidro e uma co-coluna com $0,5000 \mathrm{~g}$ de sílica, caso o ensaio correspondesse ao nível (+) do planejamento. Foram adicionados 5,0 mL de solvente extrator ao cartucho e levado ao banho ultra-sônico por 10 min à temperatura do ambiente, de forma que o cartucho ficasse mergulhado na água até a altura do solvente. Esta última etapa foi realizada somente para os ensaios pertencentes ao nível (+) deste fator. Posteriormente, foi realizada a eluição com mais $5,0 \mathrm{~mL}$ de solvente e coletadas em frascos de vidro. Aos extratos foram adicionados $50,0 \mu \mathrm{L}$ de solução do padrão interno (bifentrina) a 2,0 $\mathrm{mg} \mathrm{L}^{-1}$. O solvente foi evaporado sob corrente de ar e o extrato recuperado em 1,0 mL de acetonitrila foi analisado por cromatografia gasosa.

\section{Validação do método}

As figuras de mérito relacionadas com o processo de validação como seletividade, limite de detecção (LD), limite de quantificação (LQ), linearidade de resposta, precisão e exatidão foram determinadas conforme recomendação de agências regulatórias brasileiras ${ }^{26,27} \mathrm{e}$ de publicações relacionadas. ${ }^{28,29}$

\section{Aplicação da técnica DMFS}

O método validado foi aplicado para determinação dos agrotóxicos em amostras de tomates adquiridas em quatro pontos distintos do comércio de Viçosa-MG. Um quilo de cada amostra de tomate foi transportado para o laboratório e estocado no freezer até o momento da análise.

\section{RESULTADOS E DISCUSSÃO}

\section{Análise cromatográfica}

Na Figura 2 está representado um cromatograma da solução padrão, a $100 \mu \mathrm{g} \mathrm{L}^{-1}$, dos agrotóxicos preparados em acetonitrila. $\mathrm{O}$ pico, com tempo de retenção $\left(\mathrm{t}_{\mathrm{R}}\right)$ igual a 9,8 min corresponde à bifentrina (padrão interno). Os demais picos, com $t_{R}$ iguais a 5,7; 10,$8 ; 12,4$ e 14,1 min correspondem aos agrotóxicos clorpirifós, $\lambda$-cialotrina, cipermetrina e deltametrina, respectivamente. A presença de mais de um pico para os piretróides é atribuída à conversão em isômeros durante a injeção das amostras no cromatógrafo a gás. ${ }^{30} \mathrm{~A}$ quantificação desses piretróides foi realizada considerando-se a soma das áreas dos picos dos isômeros nos cromatogramas das amostras e dos padrões.

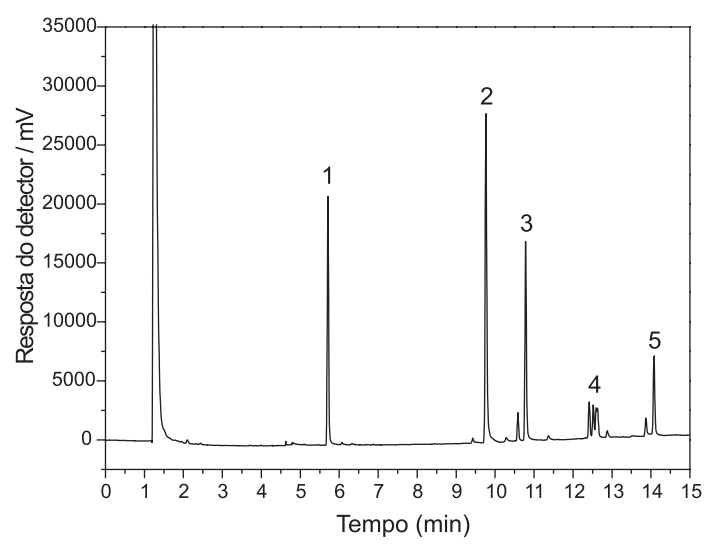

Figura 2. Cromatograma da solução padrão de 100,0 $\mu \mathrm{g} \mathrm{L}^{-1}$ dos agrotóxicos estudados, onde: $1 . t_{R}=5,7$ min - clorpirifós; $2 . t_{R}=9,8 \mathrm{~min}$ - bifentrina (padrão interno); 3. $t_{R}=10,8 \mathrm{~min}$ - $\lambda$-cialotrina; $4 . t_{R}=12,4 \mathrm{~min}$ - cipermetrina e 5 . $t_{R}=14,1$ min - deltametrin

\section{Avaliação do adsorvente e eluente para a técnica de extração DMFS}

A DMFS baseia-se na dispersão de amostras complexas, como tomate, sobre a superfície de um adsorvente. A mistura obtida (adsorvente + amostra) é transferida para uma coluna e os analitos de interesse são dessorvidos com pequena quantidade de solvente. ${ }^{25,31}$

Alguns autores têm utilizado o acetato de etila ${ }^{18,32,33}$ ou misturas de solventes, como hexano: acetona $(9: 1)^{15}$ para extração de agrotóxicos. Entretanto, a porcentagem de recuperação dos analitos e o clean up dos extratos dependem da solubilidade dos compostos no eluente e do tipo de interação do analito com a matriz e com o adsorvente utilizado na dispersão da amostra. ${ }^{25}$ Por isso, estes dois eluentes (acetato de etila e a mistura hexano: acetona (9:1)) foram combinados com quatro adsorventes de polaridades distintas para DMFS, sendo o florisil e a sílica os mais polares, e o octadecil (C-18) e octil (C-8) os de menor polaridade.

Os resultados obtidos na extração dos agrotóxicos estão apresentados na Figura 3. O acetato de etila proporcionou as maiores porcen-

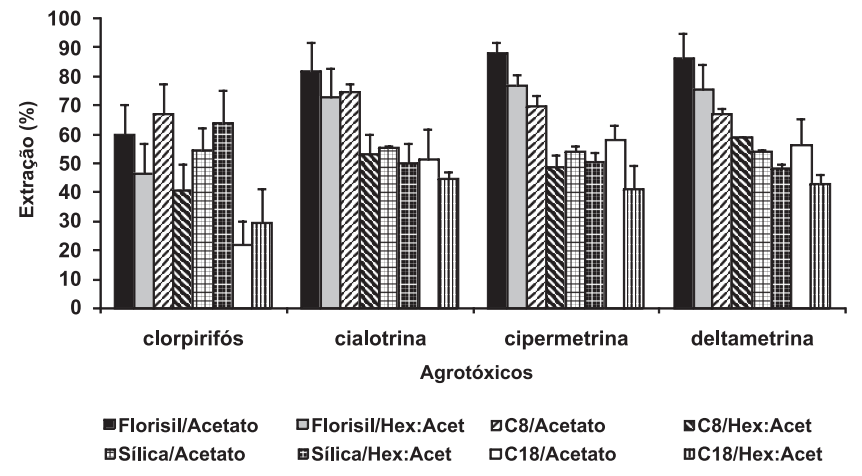

Figura 3. Porcentagem de recuperação dos agrotóxicos, obtidos após extração da amostra de tomate por DMFS, empregando diferentes adsorventes e eluente 
tagens de recuperação para os piretróides $\lambda$-cialotrina, cipermetrina e deltametrina (50 a 90\%) em relação à mistura hexano:acetona (9:1) (40 a $80 \%$ ) nos quatro adsorventes.

Dentre os adsorventes, o florisil proporcionou maiores porcentagens de recuperação dos piretróides (> 80\%) e extratos com clean up adequado para análise cromatográfica. Os piretróides interagem fracamente com a superfície do florisil devido às suas características hidrofóbicas e por isso o acetato de etila elui estes agrotóxicos mais facilmente. ${ }^{15}$

Usando o C-18 como adsorvente foram obtidos os resultados mais baixos na extração para os piretróides, quando eluídos com a mistura hexano:acetona $(9: 1)( \pm 40 \%)$. Isto se deve à forte interação dos agrotóxicos com este adsorvente, sendo estes parcialmente removidos pelo eluente. ${ }^{34} \mathrm{Na}$ extração do clorpirifós as porcentagens de recuperação foram insatisfatórias para a maioria das combinações de adsorvente e eluente analisadas (20 a 70\%), além de coeficientes de variação elevados (7 a 12\%), porém, dentro do intervalo aceito na literatura.

Embora a sílica não tenha proporcionado porcentagens de recuperação dos agrotóxicos elevadas (cerca de 50\%), este adsorvente foi o mais eficiente no clean up dos extratos. Na Figura 4 está representada uma comparação qualitativa dos cromatogramas obtidos a partir de extratos da DMFS utilizando como adsorvente sílica e C-18. O cromatograma obtido com os extratos eluídos em C-18 apresentou vários sinais de interferentes, indicando uma desvantagem deste adsorvente em relação à sílica.
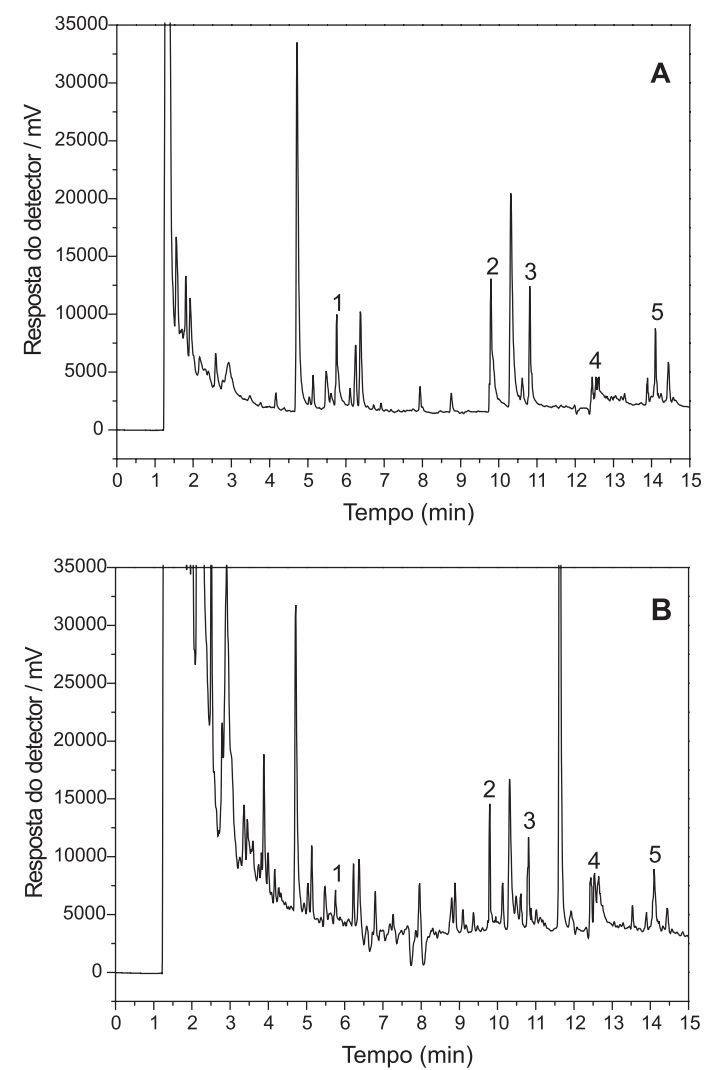

Figura 4. Comparação qualitativa dos cromatogramas obtidos com extratos da dispersão da amostra em sílica (A) e C-18 (B) utilizando como eluente acetato de etila: $1 . t_{R}=5,7 \mathrm{~min}$ - clorpirifós; $2 . t_{R}=9,8$ min bifentrina (padrão interno); 3. $t_{R}=10,8 \mathrm{~min}$ - $\lambda$-cialotrina; 4. $t_{R}=12,4 \mathrm{~min}$ - cipermetrina e 5 . $t_{R}=14,1$ min - deltametrina

\section{Avaliação do volume de solvente na extração dos agrotóxicos}

Para extratos eluídos em florisil foi observado que volumes maiores que $10,0 \mathrm{~mL}$ de acetato de etila não aumentam a eficiência da extração. Nenhuma extração significativa foi observada ao se realizar uma nova eluição no mesmo cartucho com novas quantidades do eluente. Como pode ser observado no cromatograma do segundo extrato, Figura 5, as intensidades dos sinais atribuídos aos agrotóxicos são muito baixas. Quantitativamente a maior parte dos agrotóxicos é extraída na primeira eluição (60 a 90\%). Na segunda extração esses valores não superam a $6 \%$.

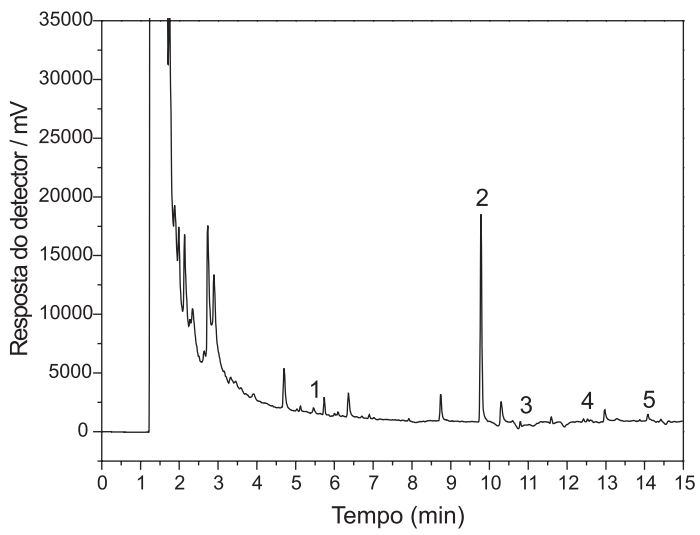

Figura 5. Cromatograma do segundo extrato (10,0 $\mathrm{mL}$ ) obtido por DMFS na extração dos agrotóxicos em tomate: 1. $t_{R}=5,7 \mathrm{~min}$ - clorpirifós (2,5\%), 2. $t_{R}=9,8 \mathrm{~min}$ - bifentrina (padrão interno), 3. $t_{R}=10,8 \mathrm{~min}-\lambda$-cialotrina $(5,7 \%)$, 4. $t_{R}=12,4$ min - cipermetrina $(5,8 \%), 5 . t_{R}=14,1 \mathrm{~min}$ - deltametrina $(3,5 \%)$

\section{Otimização da técnica dispersão da matriz em fase sólida (DMFS) para amostras de tomate}

A partir dos resultados da porcentagem de recuperação dos 8 ensaios do planejamento fatorial, realizados em duplicata, usando o programa Statistica ${ }^{\circledR}$, foi possível calcular as porcentagens de recuperação média, os efeitos de cada fator e as interações entre os fatores na extração de cada um dos agrotóxicos. Os erros associados a cada efeito e suas interações foram avaliados pelo teste $t$ para $95 \%$ de probabilidade $(\alpha=0,05)$ e 8 repetições $(n=8)$. Alguns resultados da análise estatística são apresentados na Tabela 3.

Pelos resultados da Tabela 3 conclui-se que as proporções 1:1 e 2:1 de adsorvente:amostra $(\mathrm{m} / \mathrm{m})$ não influenciam significativamente na porcentagem de recuperação dos quatro agrotóxicos pela DMFS, ao nível de $95 \%$ de probabilidade pelo teste $t$. Alguns autores, ${ }^{25,35}$ no entanto, relatam que o aumento da proporção do adsorvente contribui para o aumento da porcentagem de recuperação de alguns agrotóxicos.

A sílica foi utilizada como co-coluna em razão de sua melhor eficiência no clean up dos extratos, removendo expressivamente os componentes da matriz. Entretanto, foi verificado um efeito negativo na extração do clorpirifós, diminuindo em $7 \%$ a porcentagem de recuperação. O clorpirifós, por ser um agrotóxico mais polar, adsorve mais fortemente na sílica, durante a etapa de clean up.

Embora estatisticamente nenhuma influência significativa tenha sido verificada na extração dos piretróides, a presença da co-coluna afetou qualitativamente os cromatogramas, como pode ser observado na Figura 6. Os cromatogramas das amostras em que foram utilizadas as co-colunas têm menores ruídos em relação àqueles em que estas não foram utilizadas. É importante ressaltar que a eliminação de componentes endógenos da matriz, pela 
Tabela 3. Porcentagens de recuperação média, efeitos de cada fator e interações entre os fatores ( \pm estimativa do erro experimental) na extração de cada um dos agrotóxicos, obtidos nos experimentos do planejamento fatorial para amostras de tomate, pelo método DMFS

\begin{tabular}{|c|c|c|c|c|}
\hline & Clorpirifós & $\lambda$-cialotrina & Cipermetrina & Deltametrina \\
\hline Recuperação média & $51 \pm 1$ & $80 \pm 2$ & $87 \pm 1$ & $82 \pm 2$ \\
\hline (1) Adsorvente/Amostra & $2 \pm 3$ & $-3 \pm 3$ & $4 \pm 2$ & $-5 \pm 3$ \\
\hline (2) Uso de co-coluna & $-7 \pm 3 *$ & $7 \pm 3$ & $-2 \pm 2$ & $-0,7 \pm 3$ \\
\hline (3) Uso do banho ultra-sônico & $17 \pm 3^{*}$ & $8 \pm 3^{*}$ & $12 \pm 2 *$ & $0,0 \pm 3$ \\
\hline (1) e (2) & $6 \pm 3$ & $0,4 \pm 3$ & $-3 \pm 2$ & $-3 \pm 3$ \\
\hline (1) e (3) & $7 \pm 3^{*}$ & $5 \pm 3$ & $7 \pm 2 *$ & $5 \pm 3$ \\
\hline$(2)$ e (3) & $0,6 \pm 3$ & $-3 \pm 3$ & $0,4 \pm 2$ & $1 \pm 3$ \\
\hline (1) e (2) e (3) & $-2 \pm 3$ & $-2 \pm 3$ & $0,1 \pm 2$ & $0,03 \pm 3$ \\
\hline
\end{tabular}

* Efeito estatisticamente significativo ao nível de $95 \%$ de probabilidade pelo teste $t$.
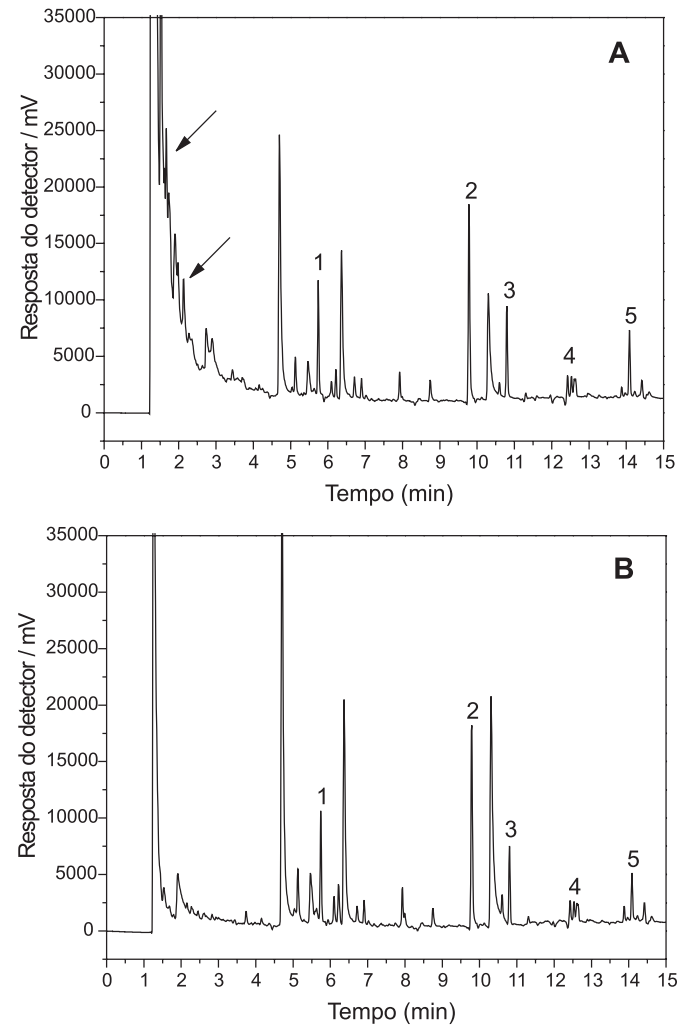

Figura 6. Cromatogramas de extratos obtidos da DMFS para o par Florisil/ Acetato de etila: A) Extração sem uso da co-coluna (sílica), B) Extração com uso da co-coluna (sílica): $1 . t_{R}=5,7 \mathrm{~min}$ - clorpirifós, $2 . t_{R}=9,8 \mathrm{~min}$ - bifentrina (padrão interno), 3. $t_{R}=10,8$ min - $\lambda$-cialotrina, $4 . t_{R}=12,4$ min - cipermetrina, 5. $t_{R}=14,1 \mathrm{~min}$ - deltametrina

presença da co-coluna, aumenta o tempo de vida útil da coluna cromatográfica.

A utilização de ultra-som é muito comum na homogeneização de amostras, por isso, neste trabalho também foi avaliada a influência deste parâmetro nas porcentagens de extração dos agrotóxicos (Tabela 3 ). As porcentagens de recuperação para clorpirifós, $\lambda$-cialotrina e cipermetrina aumentaram, respectivamente, de 16,$9 ; 8,1$ e $8,8 \%$. O aumento da eficiência da extração com auxílio do banho ultra-sônico também foi observado por Albero et al., ${ }^{36}$ na extração de organofosforados em sucos de tomate. A porcentagem de recuperação da deltametrina não foi alterada significativamente pelo uso do banho ultra-sônico.
Observou-se ainda que há um efeito de interação apenas entre os fatores (1) e (3), ou seja, quando a extração é realizada com o adsorvente em maior proporção (2:1) e o uso de banho ultra-sônico. Neste caso, as porcentagens de extração do clorpirifós e da cipermetrina aumentaram significativamente em 6,6 e 8,1\%, respectivamente. Para os outros dois agrotóxicos, $\lambda$-cialotrina e deltametrina, os aumentos foram de 4,8 e 4,7 \%, respectivamente, não sendo significativos ao nível de $95 \%$ de probabilidade pelo teste $t$.

Pelos resultados obtidos na análise estatística (Tabela 3), os ensaios 11 e 12 (Tabela 2) que correspondem aos fatores proporção adsorvente:amostra 2:1 (m/m), não utilizar co-coluna e deixar o cartucho exposto ao banho ultra-sônico foram as condições que proporcionaram as maiores porcentagens de recuperação dos agrotóxicos clorpirifós $(64,7 \pm 3,1), \lambda$-cialotrina $(88,3 \pm 2,8)$, cipermetrina $(99,2 \pm$ $0,5)$ e deltametrina $(89,2 \pm 3,8)$, em amostras de tomate por DMFS.

\section{Validação do método}

\section{Seletividade}

Os cromatogramas dos extratos apresentam uma resolução cromatográfica satisfatória e a seletividade do método foi comprovada por comparação dos cromatogramas obtidos de amostras de tomate fortificadas com amostras livres de agrotóxicos.

\section{Limite de detecção, limite de quantificação e linearidade}

$\mathrm{O}$ limite de detecção (LD) do método proposto foi determinado considerando o valor igual a pelo menos 3 vezes o sinal da linha de base (ruído) obtido para amostras de tomate isentas de agrotóxicos (branco) e analisadas por CG-ECD. O limite de quantificação (LQ) foi determinado considerando um sinal pelo menos 10 vezes maior que o sinal do ruído. Os limites de detecção para clorpirifós, $\lambda$-cialotrina, cipermetrina e deltametrina foram inferiores a $0,006 \mu \mathrm{g} \mathrm{g}^{-1}(3,0 \mu \mathrm{g}$ $\mathrm{L}^{-1}$ no extrato) e o limite de quantificação foi inferior a $0,02 \mu \mathrm{g} \mathrm{g}^{-1}$ (10,0 $\mu \mathrm{g} \mathrm{L}^{-1}$ no extrato) para todos os agrotóxicos em amostras de tomate. Desta forma, os valores de LQ foram inferiores aos limites máximos de resíduos estabelecidos pela ANVISA.

A curva analítica e os dados da regressão linear indicaram que a resposta do detector por captura de elétrons (DCE) foi linear para os quatro compostos analisados na faixa de concentração mostrada na Tabela 4, com coeficientes de correlação superiores a 0,99. Na Tabela 4 são apresentados também os dados da curva analítica, o LD e o LQ para os quatro compostos, bem como os limites máximos de resíduos (LMR).

\section{Exatidão e precisão do método}

Para determinar a exatidão do método, amostras de tomate (isentas de agrotóxicos) foram fortificadas com 0,$020 ; 0,040 ; 0,20$ 
Tabela 4. Valores de coeficiente de correlação, faixa linear, limite de detecção (LD), limite de quantificação (LQ) e limite máximo de resíduo (LMR)

\begin{tabular}{|c|c|c|c|c|c|c|}
\hline Agrotóxicos & Equação & $\mathrm{r}$ & Faixa $\left(\mu \mathrm{g} \mathrm{g}^{-1}\right)$ & $\mathrm{LD}\left(\mu \mathrm{g} \mathrm{g}^{-1}\right)$ & $\mathrm{LQ}\left(\mu \mathrm{g} \mathrm{g}^{-1}\right)$ & $\operatorname{LMR}\left(\mu \mathrm{g} \mathrm{g}^{-1}\right)$ \\
\hline Clorpirifós & $\begin{aligned} \text { (Método) } Y & =0,0062 x+0,307 \\
(\text { Detector }) & Y=0,0042 x+0,0929\end{aligned}$ & $\begin{array}{l}0,996 \\
0,998\end{array}$ & $0,012-0,90$ & 0,0036 & 0,012 & 0,5 \\
\hline$\lambda$-cialotrina & $\begin{aligned} \text { (Método) } Y & =0,0135 x-0,015 \\
\text { (Detector) } Y & =0,0040 x-0,0217\end{aligned}$ & $\begin{array}{l}0,999 \\
0,998\end{array}$ & $0,018-1,26$ & 0,0054 & 0,018 & 0,05 \\
\hline Cipermetrina & $\begin{array}{l}\text { (Método) } Y=0,0105 x+0,0192 \\
\text { (Detector) } Y=0,0023 x-0,0083\end{array}$ & $\begin{array}{l}0,999 \\
0,999\end{array}$ & $0,020-1,40$ & 0,0060 & 0,020 & 0,1 \\
\hline Deltametrina & $\begin{array}{l}\text { (Método) } Y=0,0109 x+0,0152 \\
\text { (Detector) } Y=0,0023 x-0,0144\end{array}$ & $\begin{array}{l}0,999 \\
0,999\end{array}$ & $0,020-1,40$ & 0,0060 & 0,020 & 0,03 \\
\hline
\end{tabular}

$\mu \mathrm{g}$ de agrotóxicos/g de amostra. As porcentagens de recuperação obtidas no procedimento de extração variaram de 61 a 104\%, com desvio-padrão relativo inferior a $12 \%$ (Tabela 5), que é aceitável para amostras complexas. ${ }^{28}$

A precisão foi avaliada pelo coeficiente de variação dos resultados de sete repetições do método de extração e análise dos agrotóxicos em amostras de tomate fortificadas com $0,20 \mu \mathrm{g}$ de agrotóxicos/g de amostra (Tabela 5).

Tabela 5. Porcentagem de recuperação dos agrotóxicos, obtidos após extração da amostra de tomate, fortificadas em três concentrações diferentes

\begin{tabular}{lcccc}
\hline $\begin{array}{l}\text { Concentra- } \\
\text { ção }\left(\mu \mathrm{g} \mathrm{g}^{-1}\right)\end{array}$ & \multicolumn{4}{c}{ Recuperação (\%) (média \pm DPR) } \\
\hline $0,020^{\text {a }}$ & $56,5 \pm 11,3$ & $86,6 \pm 5,5$ & $101,3 \pm 4,6$ & $111,5 \pm 0,6$ \\
$0,040^{\text {a }}$ & $54,8 \pm 11,0$ & $89,5 \pm 8,3$ & $95,5 \pm 8,0$ & $98,6 \pm 9,2$ \\
$0,20^{\text {b }}$ & $61,6 \pm 11,7$ & $90,3 \pm 7,9$ & $104,4 \pm 8,2$ & $104,9 \pm 7,4$ \\
\hline
\end{tabular}

${ }^{\text {a }}$ Resultados representam uma média de três replicatas \pm DPR.

${ }^{b}$ Resultados representam uma média de sete replicatas \pm DPR.

Depois de validado o método, quatro amostras de tomates adquiridas no comércio de Viçosa foram analisadas. Entretanto em nenhuma das amostras foi detectada a presença de resíduos dos agrotóxicos clorpirifós, $\lambda$-cialotrina, cipermetrina e deltametrina seguindo o método proposto.

\section{CONCLUSÃO}

A otimização da DMFS, para extração de agrotóxicos em tomate e análise por CG, resultou em um método rápido, eficaz e de baixo custo, com porcentagens de recuperação elevadas para os piretróides (superior a 88\%). Nessa técnica, a escolha do adsorvente e eluente foi avaliada em função das características dos agrotóxicos. Adsorventes mais polares, como o florisil, associados a eluentes menos polares (acetato de etila) contribuíram para aumentar a porcentagem de recuperação de agrotóxicos hidrofóbicos, como os piretróides -cialotrina, cipermetrina e deltametrina. Outro fator que também contribuiu para aumentar a porcentagem de recuperação foi a utilização da proporção adsorvente:amostra (2:1) associada ao uso de banho ultra-sônico na etapa de extração dos agrotóxicos.

\section{AGRADECIMENTOS}

À FAPEMIG pelo apoio financeiro, ao CNPq pela bolsa concedida a G. P. de Pinho, ao Prof. R. N. C. Guedes, do Departamento de Biologia Animal/UFV pelos padrões dos piretróides e ao Prof. C. Reis do DQ/UFV pelas sugestões durante a elaboração deste artigo.

\section{REFERÊNCIAS}

1. Penteado, S. R.; Cultivo orgânico de tomate, Aprenda Fácil: Viçosa, 2004.

2. Silva, A. C.; Carvalho, G. A. Em Tomate: produção em campo, em casa de vegetação e em hidroponia; Alvarenga, M. A. R., ed.; UFLA: Lavras, 2004, cap. 10.

3. http://sistemasdeproducao.cnptia.embrapa.br, acessada em Setembro 2007.

4. http://www.anvisa.gov.br/divulga/noticias, acessada em Julho 2007.

5. http://www.epa.gov/pesticides, acessada em Agosto 2007.

6. Silva, H. J.; Samarawickrema, N. A.; Wickremasinghe, A. R.; Trans. $R$. Soc. Trop. Med. Hyg. 2006, 100, 803.

7. Sharif, Z.; Man, Y. B. C.; Hamid, N. S. A.; Keat, C. C.; J. Chromatogr., A 2006, 1127, 254.

8. Nunes, G. S.; Santos, T. C. R.; Barceló, D.; Pimenta, A. S.; Ribeiro, M. L.; Quim. Nova 2002, 25, 214.

9. Sanusi, A.; Guilet, V.; Montury, M.; J. Chromatogr., A 2004, 1046, 35.

10. Valente, A. L. P.; Augusto, F.; Quim. Nova 2000, 23, 523.

11. Krutz, L. J.; Senseman, S. A.; Sciumbato, A. S. J.; J. Chromatogr., A 2003, 999, 103.

12. Albero, B.; Sánchez-Brunete, C.; Tadeo, J. L.; Talanta 2005, 66, 917.

13. Lanças, F. M.; Extração em fase sólida, Rima: São Carlos, 2004.

14. Barker, S. A.; Long, A. R.; Short, C. R.; J. Chromatogr., A 1989, 475, 353.

15. Ling, Y. C.; Huang, I. P.; J. .Chromatogr., A 1995, 695, 75.

16. Sanchez-Brunete, C.; Albero, B.; Miguel, E.; Tadeo, J. L.; J. AOAC Int. 2002, 85, 128.

17. Hu, Y.; Zheng, P.; He, H.; Sheng, G.; J. Chromatogr., A 2005, 1098, 188.

18. Torres, C. M.; Pico, Y.; Redondo, M. J.; Mañes, J.; J. Chromatogr., A 1996, 719,95 .

19. Torres, C. M.; Picó, Y.; Mañes, J.; J. Chromatogr., A 1997, 778, 127.

20. Perret, D.; Gentili, A.; Marchese, S.; Sergi, M.; D`Ascenzo, G.; J. AOAC Int. 2002, 85, 724.

21. Dórea, H. S.; Lopes, W. G.; Quim. Nova 2004, 27, 282.

22. Kristenson, E. M.; Haverkate, E. G. J.; Slooten, C. J.; Ramos, L.; Vreuls, R. J. J.; Brinkman, U. A. Th.; J. Chromatogr., A 2001, 917, 277.

23. Barros Neto, B.; Scarminio, I. S.; Bruns, R. E.; Como fazer experimentos - Pesquisa e desenvolvimento na ciência e na indústria, Unicamp: Campinas, 2001.

24. Teófilo, R. F.; Ferreira, M. M. C.; Quim. Nova 2006, 29, 338.

25. Barker, S. A.; J. Chromatogr., A 2000, 880, 63.

26. Agência Nacional de Vigilância Sanitária (ANVISA); Resolução 899 de 29 de maio de 2003 - Guia para Validação de Métodos Analíticos e Bioanalíticos.

27. Instituto Nacional de Metrologia, Normalização e Qualidade Industrial (INMETRO); Orientações sobre Validação de Métodos de Ensaios Químicos, DOQ-CGCRE-008, 2003. 
28. Ribani, M.; Bottoli, C. B. G.; Collins, C. H.; Jardim, I. C. S. F.; Melo, L. F. C.; Quim. Nova 2004, 27, 771.

29. Lanças, F. M.; Validação de métodos cromatográficos de análise Métodos Cromatográficos de Análise 6, Rima: São Paulo, 2004.

30. Mastovská, K.; Lehotay, S. J.; J. Chromatogr., A 2004, 1040, 259.

31. Barker, S. A.; J. Chromatogr., A 2000, 885, 115.

32. Dórea, H. S.; Lanças, F. M.; J. Microcol. Sep. 1999, 11, 367.
33. Navarro, M.; Picó, Y.; Marín, R.; Mañes, J.; J. Chromatogr., A 2002, 968, 201.

34. Pang, G. F.; Fan, C. L.; Chao, Y. Z.; Zhao, T. S.; J. Chromatogr, A 1994, 667,348 .

35. Pensado, L.; Casais, M. C.; Mejuto, M. C.; Cela, R.; J. Chromatogr., A 2005, 1077, 103.

36. Albero, B.; Brunete, C. S.; Tadeo, J. L.; J. Chromatogr., A 2003, 1007, 137. 